\title{
$\infty \sqrt{1}$ Stroke and \\ Decline in stroke alerts and hospitalisations during the COVID-19 pandemic
}

Malveeka Sharma (D) , ${ }^{1}$ Vasileios-Arsenios Lioutas (D) , ${ }^{2}$ Tracy Madsen, ${ }^{3}$ Judith Clark, ${ }^{4}$ Jillian O'Sullivan, ${ }^{2}$ Mitchell S. V. Elkind, ${ }^{5,6}$ Joshua Z. Willey, ${ }^{5}$ Randolph S. Marshall, ${ }^{5}$ Magdy H. Selim, ${ }^{2}$ David Greer, ${ }^{4}$ David L. Tirschwell, ${ }^{1}$ Tina Burton, ${ }^{7}$ Amelia Boehme, ${ }^{5,6}$ Hugo J. Aparicio ${ }^{4}$

To cite: Sharma M, Lioutas V-A, Madsen T, et al. Decline in stroke alerts and hospitalisations during the COVID-19 pandemic. Stroke \& Vascular Neurology 2020;5: e000441. doi:10.1136/svn2020-000441

Received 30 May 2020 Revised 29 July 2020 Accepted 4 August 2020 Published Online First 27 August 2020

\section{Check for updates}

(C) Author(s) (or their employer(s)) 2020. Re-use permitted under CC BY-NC. No commercial re-use. See rights and permissions. Published by BMJ.

For numbered affiliations see end of article.

Correspondence to Dr Hugo J. Aparicio; hugoa@bu.edu

\section{ABSTRACT}

Introduction Patients with stroke-like symptoms may be underutilising emergency medical services and avoiding hospitalisation during the COVID-19 pandemic. We investigated a decline in admissions for stroke and transient ischaemic attack (TIA) and emergency department (ED) stroke alert activations.

Methods We retrospectively compiled total weekly hospital admissions for stroke and TIA between 31 December 2018 and 21 April 2019 versus 30 December 2019 and 19 April 2020 at five US tertiary academic comprehensive stroke centres in cities with early COVID-19 outbreaks in Boston, New York City, Providence and Seattle. We collected available data on ED stroke alerts, stroke severity using the National Institutes of Health Stroke Scale (NIHSS) and time from symptom onset to hospital arrival. Results Compared with 31 December 2018 to 21 April 2019, a decline in stroke/TIA admissions and ED stroke alerts occurred during 30 December 2019 to 19 April 2020 ( $p$ trend $<0.001$ for each). The declines coincided with state stay-at-home recommendations in late March. The greatest decline in hospital admissions was observed between 23 March and 19 April 2020, with a 31\% decline compared with the corresponding weeks in 2019. Three of the five centres with 2019 and 2020 stroke alert data had a $46 \%$ decline in ED stroke alerts in late March and April 2020, compared with 2019. Median baseline NIHSS during these 4 weeks was 10 in 2020 and 7 in 2019. There was no difference in time from symptom onset to hospital arrival.

Conclusion At these five large academic US hospitals, admissions for stroke and TIA declined during the COVID-19 pandemic. There was a trend for fewer ED stroke alerts at three of the five centres with available 2019 and 2020 data. Acute stroke therapies are time-sensitive, so decreased healthcare access or utilisation may lead to more disabling or fatal strokes, or more severe nonneurological complications related to stroke. Our findings underscore the indirect effects of this pandemic. Public health officials, hospital systems and healthcare providers must continue to encourage patients with stroke to seek acute care during this crisis.

\section{INTRODUCTION}

The WHO declared COVID-19 a pandemic on 11 March 2020 and the USA declared a national emergency over COVID-19 on 13 March. Reports examining the effect of the pandemic on healthcare delivery for nonCOVID conditions are emerging, ${ }^{1-5}$ including observations of fewer mechanical thrombectomy procedures being performed for acute ischaemic stroke and on delays in stroke care. We hypothesised a decline in admissions for stroke and transient ischaemic attack (TIA) and emergency department (ED) stroke alert activations.

\section{METHODS}

We retrospectively compiled total weekly hospital admissions for stroke and TIA and ED stroke alert activations between 31 December 2018 and 21 April 2019 versus 30 December 2019 and 19 April 2020. Hospital admission data were collected at five US tertiary academic comprehensive stroke centres in cities with early COVID-19 outbreaks in Boston, New York City, Providence and Seattle. Hospital capacities ranged from 413 to 719 beds with a combined catchment population of 3-4 million. Data for ED stroke alerts were available from three of the stroke centres in New York City, Providence and Seattle.

Hospital admissions included ischaemic stroke, intracerebral haemorrhage, subarachnoid haemorrhage or TIA, including transfers. Stroke alert was defined as stroke team notification of an ED patient with stroke-like symptoms within 24 hours of presentation. We collected data on baseline stroke severity using the National Institutes of Health Stroke Scale (NIHSS) and data on time from symptom onset to hospital arrival for patients with ischaemic and haemorrhagic stroke, excluding patients with TIA and those presenting over 24 hours after symptom onset.

Hospital admissions for stroke and TIA, ED stroke alerts, baseline NIHSS and time from 


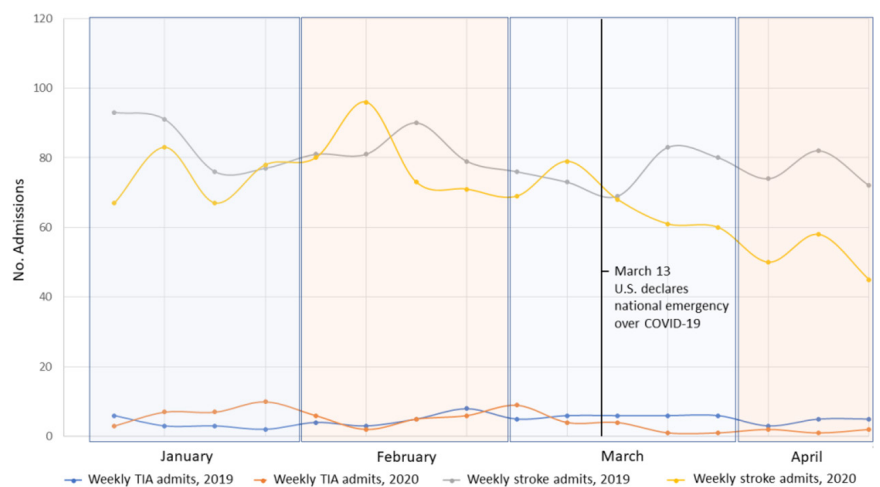

Figure 1 Weekly admissions for stroke and transient ischaemic attack (TIA) in the first 16 weeks of 2019 and 2020. Data from five medical centres in Boston, New York City, Providence and Seattle.

symptom onset to hospital arrival were compared using $t$-test, Fisher's exact test or Wilcoxon rank-sum test, where appropriate. Univariate analyses were restricted to the weeks after a national emergency was declared (after 13 March). In our primary analysis, over the total 16-week period, time series regression models (autoregressive integrated moving average) and time series forecasting systems were used to assess the inter-relationship of weekly stroke/TIA admissions and ED stroke alerts, separately. The standard variation of weekly stroke alerts and admissions were compared with the same measures in 2019.

\section{RESULTS}

Trends in weekly stroke and TIA admissions are displayed in figure 1. Compared with the 31 December 2018 to 21 April 2019 time period, there was a decline in admissions observed between 30 December 2019 and 19 April 2020 ( $p$ trend $<0.001$ ). The decline coincided with the declaration of a US national emergency over the COVID-19 pandemic on 13 March, and with state stay-at-home recommendations in New York, Washington, Massachusetts and Rhode Islands (22, 23, 24 and 28 March, respectively). The greatest decline in stroke and TIA admissions was seen between 23 March and 19 April 2020, with a total of 281 admissions, compared with 410 in the corresponding time period in 2019, representing $31 \%$ fewer admissions (table 1).

At three of the five centres with data on ED stroke alert activations from both 2019 and 2020 (figure 2), we observed a decline in the first 16 weeks of 2020, compared with 2019 ( $p$ trend $<0.001$ ). There was a $46 \%$ decline in stroke alerts in late March and April, compared with 2019 (table 1).

The median NIHSS for all centres between 23 March and 19 April 2020 was 10, compared with a median score of 7 for the corresponding weeks in 2019. The median time from symptom onset to hospital arrival did not appear to differ between 23 March and 19 April 2020 and 25 March and 21 April 2019 (6.9 and 7.6 hours, respectively).
Table 1 Stroke and TIA admissions, emergency department stroke alerts, stroke severity and delay to hospital presentation during the COVID-19 pandemic at US medical centres

\begin{tabular}{|c|c|c|}
\hline & $\begin{array}{l}2019 \\
25 \text { March to } 21 \\
\text { April }\end{array}$ & $\begin{array}{l}2020 \\
23 \text { March to } \\
19 \text { April* }^{*}\end{array}$ \\
\hline Stroke/TIA admissions, $n$ & 410 & 281 \\
\hline Stroke only† & 391 & 274 \\
\hline TIA only & 19 & 7 \\
\hline ED stroke alerts, $n \ddagger$ & 561 & 301 \\
\hline $\begin{array}{l}\text { Baseline NIHSS, median } \\
\text { score (range) }\end{array}$ & $7(7-10)$ & $10(8-11)$ \\
\hline $\begin{array}{l}\text { Stroke symptom onset to } \\
\text { hospital arrival, median } \\
\text { hours (range) }\end{array}$ & $6.9(5.4-8.0)$ & $7.6(4.9-12.5)$ \\
\hline
\end{tabular}

*Univariate analyses comparing 2020 with 2019 measures were statistically significant $(p<0.01)$, except for median time from stroke symptom onset to hospital arrival $(p=0.14)$.

†Includes admissions for ischaemic stroke, intracerebral haemorrhage and subarachnoid haemorrhage.

fIncluding three medical centres in New York City, Providence and Seattle with available data.

ED, emergency department; NIHSS, National Institutes of Health Stroke Scale; TIA, transient ischaemic attack.

\section{DISCUSSION}

In this multicentre study, admissions for stroke and TIA and ED stroke alerts declined during the COVID-19 pandemic. Patients with stroke may be reluctant to activate emergency services or present to hospitals for fear of exposure to COVID-19. They may be underestimating their risk of death or disability due to stroke and avoiding hospital and emergency systems which they assume are under stress. Citing fear of in-hospital infection and disrupted functioning at stroke centres in China and France, separate groups have described a decline, between $21 \%$ and $50 \%$, in the number of mechanical thrombectomy cases performed during the first weeks of the outbreak. ${ }^{36}$ In a recent report, individuals undergoing

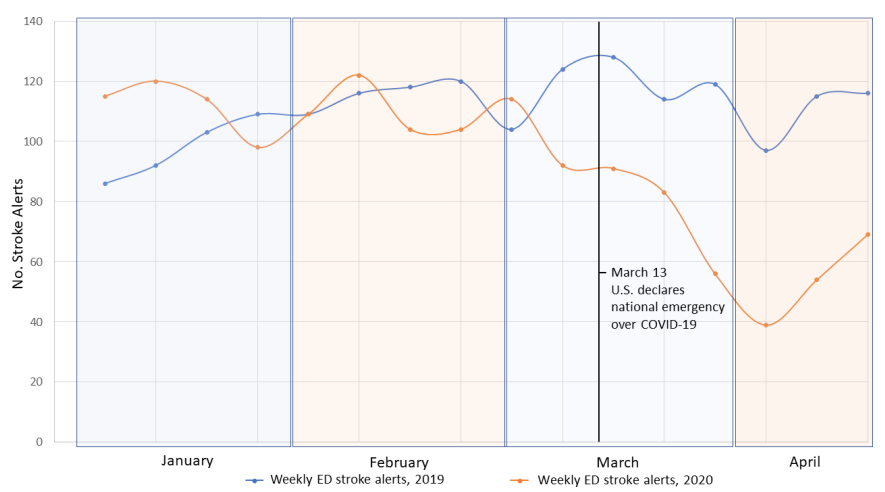

Figure 2 Weekly emergency department (ED) stroke alert activations in the first 16 weeks of 2019 and 2020. Data from three medical centres in New York City, Providence and Seattle. 
acute stroke imaging, as a surrogate for stroke evaluation, declined by $39 \%$ in late March. ${ }^{2}$ This was observed across all age and sex subgroups.

Additional factors may be contributing. Patients with milder stroke symptoms may be avoiding medical care. ${ }^{7}$ We noted an increase in median NIHSS scores, from 7 to 10, in late March of 2019 and 2020, suggesting an increase in the severity of stroke cases. Another contributing factor may be that because family members or bystanders usually activate emergency services, ${ }^{8}$ stay-athome and social distancing practices may lead to a lack of contact with others and under-reporting of symptoms. However, we did not find a noticeable delay in stroke symptom onset to hospital presentation among patients presenting within 24 hours of symptoms. Additionally, outpatient clinics have also cancelled in-person visits, which could result in suboptimal recognition of stroke in the community. Finally, urban flight in the hardest hit cities may have resulted in fewer strokes in metropolitan areas. A limitation is that our findings may not be representative of smaller community or rural hospitals.

\section{CONCLUSIONS}

Acute stroke therapies are time-sensitive, ${ }^{9}$ so decreased healthcare access or utilisation may lead to more disabling or fatal strokes, or more severe non-neurological complications related to stroke. Our findings underscore the indirect effects of this pandemic. Public health officials, hospital systems and healthcare providers must continue to encourage patients with stroke to seek acute care during this crisis. Future investigations using stroke registries, national admissions data and stroke mortality estimates will help elucidate where all the missing strokes have gone.

\section{Author affiliations}

${ }^{1}$ Department of Neurology, University of Washington School of Medicine, Seattle, Washington, USA

${ }^{2}$ Department of Neurology, Beth Israel Deaconess Medical Center, Harvard Medical School, Boston, Massachusetts, USA

${ }^{3}$ Deparment of Emergency Medicine, Brown University, Providence, Rhode Island, USA

${ }^{4}$ Department of Neurology, Boston University School of Medicine, Boston,

Massachusetts, USA

${ }^{5}$ Department of Neurology, Vagelos College of Physicians and Surgeon, Columbia University, New York, New York, USA

${ }^{6}$ Department of Epidemiology, Mailman School of Public Health, Columbia University, New York, New York, USA

${ }^{7}$ Department of Neurology, Brown University, Providence, Rhode Island, USA

Contributors Study conception and design of work: Malveeka Sharma, MD, MPH; Vasileios Lioutas, MD; Tracy Madsen, MD, ScM; Tina M. Burton, MD; Amelia
Boehme, PhD; Hugo J. Aparicio, MD, MPH. Data acquisition: Malveeka Sharma, MD, MPH; Vasileios Lioutas, MD; Tracy Madsen, MD, ScM; Judith Clark, Jillian 0'Sullivan, Mitchell S. V. Elkind, MD, MS; Joshua Z. Willey, MD; Randolph S. Marshall, MD, Magdy H. Selim, MD, PhD; David Greer, MD, MA; David L. Tirschwell, MD, MSc; Tina M. Burton, MD; Amelia Boehme, PhD; Hugo J. Aparicio, MD, MPH. Data analysis and interpretation: Malveeka Sharma, MD, MPH; Vasileios Lioutas, MD; Tracy Madsen, MD, ScM; Tina M. Burton, MD; Amelia Boehme, PhD; Hugo J. Aparicio, MD, MPH. Statistical analysis: Amelia Boehme, PhD. Manuscript preparation: Malveeka Sharma, MD, MPH; Vasileios Lioutas, MD; Tracy Madsen, MD, ScM; Judith Clark, Jillian O'Sullivan, Tina M. Burton, MD; Amelia Boehme, PhD; Hugo J. Aparicio, MD, MPH. Manuscript editing: Malveeka Sharma, MD, MPH; Vasileios Lioutas, MD; Tracy Madsen, MD, ScM; Judith Clark, Jillian O'Sullivan, Mitchell S. V. Elkind, MD, MS; Joshua Z. Willey, MD; Randolph S. Marshall, MD; Magdy H. Selim, MD, PhD; David Greer, MD, MA; David L. Tirschwell, MD, MSc; Tina M. Burton, MD; Amelia Boehme, PhD; Hugo J. Aparicio, MD, MPH.

Funding This research is supported by the National Institutes of Health (NIH 1UL1TR001430). Dr. Aparicio is supported by the Boston University Aram V. Chobanian Assistant Professorship.

Competing interests None declared.

Patient consent for publication Not required.

Ethics approval The institutional review boards at each centre approved the study and received approval from the ethical standards committee to conduct this study. Provenance and peer review Not commissioned; externally peer reviewed.

Open access This is an open access article distributed in accordance with the Creative Commons Attribution Non Commercial (CC BY-NC 4.0) license, which permits others to distribute, remix, adapt, build upon this work non-commercially, and license their derivative works on different terms, provided the original work is properly cited, appropriate credit is given, any changes made indicated, and the use is non-commercial. See: http://creativecommons.org/licenses/by-nc/4.0/.

ORCID iDs

Malveeka Sharma http://orcid.org/0000-0001-5638-3045

Vasileios-Arsenios Lioutas http://orcid.org/0000-0002-8521-0036

\section{REFERENCES}

1 Garcia S, Albaghdadi MS, Meraj PM, et al. Reduction in STsegment elevation cardiac catheterization laboratory activations in the United States during COVID-19 pandemic. J Am Coll Cardiol 2020;75:S0735109720349135.

2 Kansagra AP, Goyal MS, Hamilton S, et al. Collateral effect of Covid-19 on stroke evaluation in the United States. N Engl J Med 2020;383:400-1.

3 Kerleroux B, Fabacher T, Bricout N, et al. Mechanical thrombectomy for acute ischemic stroke amid the COVID-19 outbreak: decreased activity, and increased care delays. Stroke 2020;51:1-3.

4 Teo K-C, Leung WCY, Wong Y-K, et al. Delays in stroke onset to hospital arrival time during COVID-19. Stroke 2020;51:2228-31.

5 Uchino K, Kolikonda MK, Brown D, et al. Decline in stroke presentations during COVID-19 surge. Stroke 2020;51:2544-7.

6 Zhao J, Rudd A, Liu R. Challenges and potential solutions of stroke care during the coronavirus disease 2019 (COVID-19) outbreak. Stroke 2020;51:1356-7.

7 Diegoli H, Magalhães PSC, Martins SCO, et al. Decrease in hospital admissions for transient ischemic attack, mild, and moderate stroke during the COVID-19 era. Stroke 2020;51:2315-21.

8 Porteous GH, Corry MD, Smith WS. Emergency medical services dispatcher identification of stroke and transient ischemic attack. Prehosp Emerg Care 1999;3:211-6.

9 Saver JL, Fonarow GC, Smith EE, et al. Time to treatment with intravenous tissue plasminogen activator and outcome from acute ischemic stroke. JAMA 2013;309:2480-8. 